BEHIND THE TIMES 



\title{
BEHIND THE TIMES
}

\author{
VIRGINIA WOOLF IN \\ LATE-VICTORIAN CONTEXTS
}

MARY JEAN CORBETT 


\section{Copyright (C) 2020 by Cornell University}

All rights reserved. Except for brief quotations in a review, this book, or parts thereof, must not be reproduced in any form without permission in writing from the publisher. For information, address Cornell University Press, Sage House, 512 East State Street, Ithaca, New York 14850. Visit our website at cornellpress.cornell.edu.

First published 2020 by Cornell University Press

Library of Congress Cataloging-in-Publication Data

Names: Corbett, Mary Jean, 1962- author.

Title: Behind the times : Virginia Woolf in late-Victorian contexts / Mary Jean Corbett.

Description: Ithaca [New York] : Cornell University Press, 2020. Includes bibliographical references and index.

Identifiers: LCCN 2020007235 (print) | LCCN 2020007236 (ebook) | ISBN 9781501752469 (hardcover) | ISBN 9781501752483 (pdf) | ISBN 9781501752476 (epub)

Subjects: LCSH: Woolf, Virginia, 1882-1941-Criticism and interpretation. | Woolf, Virginia, 1882-1941. | Women authors-Political and social views19th century. | Women authors, English—19th century. | Feminism and literature-History-19th century. Classification: LCC PR6045.O72 Z578827 2020 (print) | LCC PR6045.O72 (ebook) | DDC 823/.912-dc23

LC record available at https: / / lccn.loc.gov/2020007235

LC ebook record available at https://1ccn.loc.gov / 2020007236

Cover image: Virginia Woolf by Ray Strachey, oil on board, late 1920s. NPG D256. (C) National Portrait Gallery, London. Used by permission. 